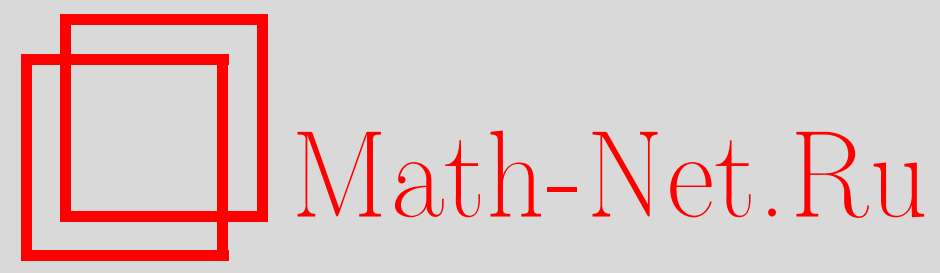

Е. В. Панфилова, Новые книги, Теория вероятн. и ее примен., 1996, том 41, выпуск 3, 717

DOI: https://doi.org/10.4213/tvp3191

Использование Общероссийского математического портала Math-Net.Ru подразумевает, что вы прочитали и согласны с пользовательским соглашением http://www . mathnet.ru/rus/agreement

Параметры загрузки:

IP: 54.224 .60 .19

26 апреля 2023 г., 17:01:28

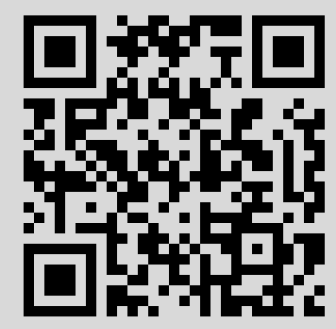




\section{Новые книги}

Глобальны й и стохастический анализ Сб. Борисович Ю. Г., Гликлих Ю. Е. (ред.). Воронеж, «Изд-во Воронеж. ун-та», 1995, 92 с. (Новое в глобальном анализе).

Д а в д О в Ю. А. и д р. Локальные свойства распределений стохастических фуякчиояалов. М., «Наука», Физматлит, 1995, 255 с. (Теория вероятностей и математическая статистика. Вып. 46).

Л е 6 е д е в В. А. Мартинаалы, сходимость вероятностных мер и стохастические уравкенин. М., «Изд-во МАИ», 1996, 347 с.

Л и фш и ц М. А. Гауссовские случайные функиии. Киев, «ТВиМС», 1995, 246 с. (Теория вероятностей и математичесхая статистика).

Те ория вероятностей и т те матическая стат и с т и к а. Киев, Вып. $51,1994,161$ с., илл.

те орияероятностей и математическаястати с т и к а. Киев, Вып. 52, 1992, 160 с.

Advances in stochastic modelling and data a n a l y si s. Ed. by Janssen J. et al. Dordrecht etc., Kluwer acad. publ. Cop. $1995, \mathrm{X}, 428$ p. (International symposium on applied stoch astic models and data analysis 6 ; 1993, Chania).

B e $\mathbf{r}$ J. v a $\mathbf{n}$ e $n$, E $\mathbf{r}$ a $\mathbf{k}$ o $v$ A. A new lower bound for the critical probability of site percolation on the square lattice. Amsterdam, 1995, 14 p. (Report centrum voor wiscunde en informatica, Dep. of operations research, statistics, a. system theory).

$\mathrm{B}$ i a n e F., D u r r e t $\mathbf{t}$. Lectures on probability theory. Ecole d'ete de probabilities de Saint-Flour XXXII-1993. Ed. Bernard P. Berlin etc., Springer, Cop., 1995, 210 p., (Lecture notes in mathematics. Vol. 1608).

B ranching processes. Proc. of the First World congr. Ed. Heyde C. C. New York etc., Springer, Cop., 1995, 179 p., (Lecture notes in mathematics. Vol. 99).

Computations with Markov chains. Proc. of the 2nd intern, workshop on the numerical solution of Markov chains. Ed. Stewart William J. Boston etc., Kluwer acad. publ., Cop., 1995, XVI, 600 p.

Панфилова Е. В. 